\title{
To Investigate The Contribution Of Steel Reinforcement In Corner Region Of Masorny Wall For Improving Key Connection
}

\author{
${ }^{1}$ Sandeep Verma, ${ }^{2}$ Bibhas Paul \\ ${ }^{1}$ Post Graduate Student, Department of CE, Jaypee University of Information Technology, Waknaghat, Solan, \\ H.P. \\ ${ }^{2}$ Assistant Professor, Department of CE, Jaypee University of Information Technology, Waknaghat, Solan, H.P.
}

\begin{abstract}
The use of masonry infill wall for load bearing structures is quite common practice in low seismic zones, while in the high seismic zones these are used for partition walls only. The lack of seismic standards of masonry and lack of proper design parameters has made this construction practices totally empirical based. To give aesthetic architectural look, requirements of structural system increases and for the masonry construction this lacks with limited available data of design. Studies in the past have shown during earthquake masonry structures fail more in number than framed structures due to rough design and bad execution techniques.

To improve the performance of masonry structures during earthquake, we need to understand its expected failures and reasons behind them. One of the failure i.e. in-plane and out of plane failure of masonry walls are very common. To improve this failure one need to improve the connection between the long wall and short wall. So that when earthquake comes, a rigid connection between walls can be introduced. This connection will help in providing resistance in between junction of long walls and short walls. When long wall faces earthquake, it comes under action of shear force and force tends to move its top portion away from its original position. If there is not properly designed key connection between these two walls, the long wall will fail at early age of loading. In case if there is strong key connection between these two walls, short wall will provide support to the long wall and increase its capacity to withstand an earthquake and vice versa. To ensure this rigid connection bricks are laid in bonds. But to make it more strong, one can use steel reinforcement in layer wise having Lshaped in plan at suitable vertical center to center distance also keeping economy in design. Resulted shear force, displacements, shear stresses and energy dissipation parameters satisfy the improved behavior of connection due to presence of steel reinforcement at suitable c/c vertical distance.
\end{abstract}

Keywords: Infill wall, reinforcement, Abaqus, brick, mortar.

\section{Introduction}

Brick masonry is commonly used in the building construction as infill also in the foundation work in the case of load bearing walls. Masonry is commonly used in the walls of buildings, retaining walls, foundations, architectural purposes and many more purposes in the buildings. As the construction of masonry includes placing it in position one by one as individual units, masonry construction tends to be quite intensive. The basic materials of masonry like cement, brick, stone and masonry construction tends to be durable construction and often requires little maintenance.

Masonry buildings are common practice in a structure. Due to strong in compression and weak in tension, structures built with masonry also known as brittle structures up to standards of designs are achieved. These are most susceptible to damage and most vulnerable part of the structure which cause deformation under earthquakes. Most of the masonry buildings in India are made up of fired clay bricks. These construction practices are engineered or non - engineered. But most of the construction practices of masonry building are non - engineered. Construction is set up with bricks without considering need of any technical aspect. Mostly these are constructed to take compressive loads during their life period. But structural integrity of these becomes major issue during earthquake. In earthquake, it causes lateral forces in the structure which finally leads to the different failure modes of the structure due to its bad characteristics for lateral loading. So finally we need to strengthen up these building to improve its performance.

\section{A. Behavior:}

Ground vibrations during earthquake cause inertial forces at the location of the mass location in the building. The force of earthquake and generated inertial forces are opposite in direction so it causes shear stresses in in-plane walls and bending stresses in out of plane walls. The generated inertial forces at the roof level travel to the foundation through the roof - wall - foundation system. Out of these three components, walls are most vulnerable to damage by the horizontal forces due to its low shear and tensile strength. The existing masonry buildings are mostly unreinforced, that is, they don't have embedded the reinforcing bars. The vulnerability of unreinforced masonry to seismic forces arises due to its low shear and tensile strength. Wall 
lying in the direction of earthquake is called strong wall and wall perpendicular to the direction of earthquake is called weak walls. Weak walls topple down if pushed laterally at the top. Toppling failure, results in bending stress. This bending stresses is resulted by the inertial forces due to earthquake which acts at the mass center and try to push the diaphragm opposite to the earthquake direction. So the connection between walls and diaphragm leads wall along with it. Finally bending stresses in the weak walls resulted.

To avoid deformation, walls need to behave as a single unit so as to provide better structural integrity. This configuration will help to take advantage of good lateral resistance of strong walls to the weak walls.

\section{B. Behavior Improvement:}

The basic need to improve behavior of masonry structure is proper interlocking box connection at junctions, roof level, lintel level and plinth level. So major challenge is how to ensure this connection?

A number of techniques with application of different material help in achieving this need. In this study concern is given to improve the box connection at the junction.

\section{Failure modes in the Masonry:}

Due to the earthquake loading, it causes inertial forces set up in the structure at mass level in the opposite direction to the earthquake direction. Due to opposite direction of these two forces results in the shear stresses and bending stresses in the in-plane and out of plane walls respectively. Different failure modes are-

\section{Sliding Shear failure:}

It occurs in an infill wall due to sliding off the brick and mortar joint at its interface. It is caused by the low vertical load, poor mortar quality and seismic loads due to the earthquake causes shearing in the wall and resulting in the sliding. If building is jointed accurately to the foundation, next aim is for adequate resistance of the foundation itself in the form of some combination of horizontal sliding friction and in its lateral earth capacity. Most common failure of this type can be seen in the walls having poor shear strength, loaded with heavily load and load reversals may occur occasionally with along with horizontal forces.

\section{Diagonal Cracks:}

These cracks result due to combine action of the coming vertical load and generated shear and tensile stress from the earthquake.

\section{Non structural failures:}

Every structural member of the building is capable of carrying the vertical load safely also to withstand safely up to some limits is other most requirement. Non-structural members like walls, suspended ceilings, window frames should make secured against movement during the earthquake shaking. Failure of these members not cause to the building collapse but it still might cause danger for occupants and requires costly replacements or repair. Due to less resisting strength of structural members like interior partitions, windows and similar building elements are often subjected shear stresses during earthquake.

\section{Failure due to overturning:}

A wall having its thickness is less than its height and length is particularly vulnerable to shaking in its weak direction. For avoiding toppling of a masonry wall, its length-to-thickness and height-to-thickness ratios should be designed carefully.

\section{Lirerature Review}

- 1 Maske, Sachin G., and Dr PS Pajgade Inamdar (2013) studied on the topic "Torsional Behaviour of Asymmetrical Buildings". The structural analysis and design of four storey RC asymmetrical frame building has been done with the help of ETAB software. The building is assumed as shopping complex. Linear static analysis has been done. The structure is assumed to be located in seismic zone IV on a site with the medium soil. Two cases are there. In CASE-1, seismic analysis of the building is done without considering design eccentricity. In CASE-2, seismic analysis of the building is done by considering torsion in the structure. For the case-1, modelling is done in the ETAB and the linear static analysis performed. While in the case-2, modelling is done on same way as in case-1 but calculations for design eccentricity is carried out here and included in the analysis. It is concluded that a difference comes out when we consider design eccentricity, resulted in increase the value of moment by the addition of torsional moment due to asymmetric of the structure. It also concluded that most of the designer holds approximate analysis for the torsional analysis which is appropriate.

- $\quad{ }^{2}$ Ahmed Sayed Ahmed Tawfik Essa, Mohamed Ragai Kotp Badr, Ashraf Hasan El-Zanaty (2014), studied on the "Effect of infill wall on the ductility and behavior of high strength reinforced concrete frame". They carry out the experimental study. The mix used for the base of the frame is of M-30 and frame is of M-65. For carrying out study three infill wall prisms were taken from the same bricks for each wall. For finding 
the result, tests were performed on initial samples. The resulted strength i.e. compressive strength of the sample was found out then. In fill wall samples namely F2, F3 and F4 resulted in low ductility factor than the bare frame F1. In the infill samples namely F2, F3 and F4, ultimate lateral load resistance parameter was greater than what that is for bare frame F1. As there was decrease in the thickness of infill wall on one side and on the other side it was observed decrease in resistance of frame for lateral load. This all resulted because infill wall with small thickness takes over more buckling. The final failure occurred within small lateral load. For infill frames resulted energy dissipation was higher than what for bare frames.

- ${ }^{3}$ Dmytro Dizhur, Michael Griffith, Jason Ingham (2014), studied on the "Out-of-plane strengthening of unreinforced masonry walls using near surface mounted fibre reinforced polymer strips". For starting the project, first stage of study consisted of testing nine single leaf masonry beams. Curing had been done for 28 days. For the retrofitting of beams a single CRPF strip inserted into a groove geometry. Allow for 7 days curing, allowing the epoxy filled around CRFP strip to reach its full strength and white coating is done on face to trace the cracking pattern. Second stage of experimental study consisted of testing five walls built with either two leaf or three leaf wall thicknesses. Curing of 28 was done. The wall sample was first tested in the as built condition first and then retrofitted using the NSM CFRP retrofit techniques. All the wall samples were tested using pseudo-static loading. And the walls with W1, W2 and W3 were tested using reversed loading cycle. The wall sample i.e. W2 have an imposed load. The wall W3 contains its top brick courses were installed after 1 week of assembly due to delay by the mason. Wall W3 contains two CFRP rods on positive side and one CFRP rod on negative side. Wall W5 had two CFRP strips terminated 450mm above the base of the wall. The experimental result shows that the use of vertically orientated CFRP strips significantly increases both the flexural strength (3.05-6.21 times) and the ductility capacity of the UR walls. NSM CFRP strengthening results in increase in flexural strength of walls with overburden loads. Due to sliding shear failure of the Wall 5 , it is concluded that the termination near the wall support is not safe. For all cyclically loaded walls, high stiffness degradation noticed at low drift ratio and progressive degradation (low rate) at high drift ratio. Displacement induced debonding was seen in several tested retrofitted beams. Large change in the curvature has been ensured by out of plane debonding.

- $\quad{ }^{4}$ R. Allouzi1, A. Irfanoglu, and G. Haikal3 studied on "Non linear finite element modelling of RC Frame Masonry wall interaction under cyclic loading". New techniques are developed to catch the cyclic response of reinforced concrete (RC) frames in filled with masonry to experimental data. A finite element model (FEM) set up using ABAQUS 6.11-1. Software has the capability to model strength and stiffness degradation and simulate various types of failure modes in the in plane and out of plane direction. Continuum material models are used for concrete, steel, mortar, and bricks elements and cohesive-friction interfaces along mid thickness of mortar bed joints. The results from the models of integrated RC frame with infill wall are compared with experimental data provided. Finally the models are checked to various results. Hysteresis models of in filled RC frames are drawn and models failed by shear. Finally it was concluded that use of Continuum Concrete Damage Plasticity model has been adopted. For this cohesivefriction interface was introduced. It was capable of simulating the behavior of an RC frame with in filled frames under monotonic and cyclic loadings. Few geometric and physical properties are needed for these simulations compared to discrete model approaches. As in the discrete model, predefining the expected shear cracks (failure) and failure planes needs. Ultimately leading to the time consuming method. Develop of hysteresis models resulted from these drawn models of in filled RC frames failed by shear.

- $\quad{ }^{5}$ Hemant B. Kaushik, Durgesh C. Rai and K. Jain, M.ASCE (2007), studied "Stress-Strain characteristics of Clay Brick Masonry under uniaxial compression". The behavior of unreinforced masonry and its constituent for uni-axial compressive stress-strain behaviour, and like parameter. Also constituents, i.e., solid clay bricks and mortar, have been studied by laboratory tests. For investigating the uni-axial compressive stress-strain behavior of bricks, mortar, and masonry prisms of all samples have been constructed with different combinations of mortar and brick grades. Monotonically increasing loading apply for masonry prisms and mortar cubes and strain controlled at their top which was applied vertically by a $250 \mathrm{KN}$ load and $\pm 125 \mathrm{~mm}$ displacement capacity MTS servo-hydraulic actuator. However, brick units were tested in a 2,000 KN universal testing machine under stress- controlled loading. For the bricks stress strain curves had plotted. Stress-Strain curve for the mortar cubes and masonry cubes had plotted. Control points defining the stress strains curves of the masonry. During the study six control points were identified on the stress-strain curves of masonry in this study, which related to the experimentally observed masonry prism compressive stresses and the corresponding compressive strains. Finally the concluded results are the relation between brick, mortar, and masonry strengths studied. Effects of water absorption, initial rate of absorption, and addition of lime in the mortar on the strength and ductility of masonry were also studied. For approximate value of the elastic modulus of bricks, mortar, and masonry 300,200 , and 550 times their compressive strengths parameters are defined respectively. Increase in the 
masonry prism compressive strength was found with increase in compressive strengths of bricks and mortar. Compressive behavior of masonry with lime mortar was found to be much better than that of masonry without lime mortar. Failure strain was about $50 \%$ greater and prism strength only about $13 \%$ less than those for prisms with strong mortar.

- ${ }^{6}$ Bishnu Hari Pandey, Kimiro MEGUR have studied on "Simulation of brick masonry wall behavior under in-plane lateral loading using applied element method". Applied element method (AEM) is used for modelling. The work as we do in the finite element method is similar in nature what followed in the applied element method. Each object is divided into a number of elements of different shapes and sizes to form mesh. Method of joining the elements together is the main difference between AEM and FEM methods. In the AEM elements are connected by a series of non linear springs representing the material behavior. Descritization for brick masonry is then done to take anisotropy of the material into account. A set of square elements and mortar joints, jointed together had used to define as brick unit. For the material modelling, failure modes noted for the model are different cracking pattern of joints, sliding of brick unit mortar bed or head joints, cracking under direct tension, diagonal tensile cracking under high compression and shear, and masonry crushing. Wall behavior analyzed at end. The results that were resulted at the end were computed in contour graphs. Here AEM method's capability checked to capture the behavior of the material and its results with the practical study. The analysis of this study under different parameters of the material is also capable to set guidelines for the masonry retrofitting.

\section{Modeling:}

\section{Modeling Methods}

Modeling of any structure and getting final results are itself a challenging task. It is very difficult to draw the model as like what the structure in actual is with all the parameters defining the nature of its working. Even if someone is able to stipulate all the conditions/constraints like behavior of brick, mortar and bond between brick and mortar there is not sure that the defined behavior is as like what the structure have.

It is well known from the past researches that the presence of infill walls reduces the horizontal earthquake loading by absorbing its energy. This all results due to increase in the overall stiffness by the masonry. If centre of rigidity of the structure and the resulted inertial forces does not act closely to each other they will cause torsion. When these are closely to each other distribution of lateral forces becomes in the order of their relative stiffness. So consideration of the stiffness of infill walls becomes necessary in the dynamic analysis of structure.

To model behavior of the masonry many studies have carried out using Finite Element Analysis and Theory of Elasticity. To model the behavior between brick and mortar interface, many parameter are there depending the software which one is using. Many of the past study have carried using approximation analysis. The one best example of this is using an Equivalent Diagonal Strut. In this behavior of masonry wall is taken like a diagonal braced frame. Many of the studies have carried out for defining this strut behavior but generally defining its width always follows an approximate approach and varies researcher to researcher.

7 Asteris, P.G (2008), for modeling behavior of masonry in finite element model two methods have been developed i.e. Micro Model and Macro Model.

Micro Model Method: - This is a method of Finite Element Method in which the each component are modeled separately like contact surface, slippage and separation etc. Results of this method are very conservation with great accuracy but the only disadvantage is that it takes more time to run analysis completely.

Macro Model Method: - This method is also known as Simplified model/Equivalent diagonal strut method. For analyzing overall behavior of masonry a diagonal strut is modeled. The number of struts using for modeling depends on the researcher to researcher. The only disadvantage of this method is that it will lack in defining the behavior of infill if there is any opening.

\section{Micro Model}

In Finite Element Method (FEM), problem/domain is discritized into a number of small well defined size components. Following the material properties defined and following the boundary conditions for the domain. As this method is generally used on a small part the problem, it requires a lot time for complete analysis. Some research on infill frame modeling is:-

${ }^{8}$ Madan et. al. (1985), in this study the investigation of the elastic behavior of a single story infill frame with opening had carried out. For defining the parameters like slip, separation and frictional loss and deboning of bond between mortar and brick a link element has adopted. In the link element, control over forces (axial \& shear) and moments have achieved for getting actual behavior of the domain. For defining the opening model was achieved by assigning very low value of infill thickness, young's modulus of elasticity and having high value for poison's ratio. It was find out that as there is an increase in the size of opening, lateral stiffness of the 
structure is reducing. At the corners of the opening principal stresses are maximum. Also he concluded that for the infill wall with opening, equivalent diagonal strut is not applicable.

${ }^{9}$ Bell (1991), in this study the application of FE model to access the cracking effect and the separation of brick and mortar. In the modeling, cracking with its location, separation i.e. slips and stiffness has defined. Results shows that the decrease in the bending moment and in the deflection with increase in the stiffness of the masonry. But the bending moment increased with the crack depth. On the un-cracked section bending moment is increasing when crack size on the cracked section is increasing. The principal stresses also changes as change in the crack depth and related failure property.

\section{Macro Model}

The main disadvantage of Macro modeling is that whole structure behavior is analyzed as a whole which doesn't include catching its minor behaviors. The time consumption and problem complexity is less than last method here. Hence for macro modeling of infill wall strut behavior was modeled and its behavior also checked with the experimental results.

${ }^{10}$ Polyakov (1960), the equivalent diagonal strut concept has studied. For this a three story building was analyzed. For defining one of the expected behavior of infill i.e. cracks along diagonal length of panel defined. The results show that the stresses from the peripheral members to masonry were transferred by compression corner of the frame infill interface.

\section{Importance of Finite Element Modeling:}

To know the behavior of a reinforced concrete building for non linear analysis it becomes very difficult to analyze domain. All this problems has lead researchers to come up with many approximate empirical relations. All theses relations are based on experiments hold with the related aim.

Finite Element Method provides flexibility in analyzing and designing with and without consideration of dynamic analysis within a short time. Also it provides user to facilitate with the different methods and parameters of analyzing. For a general R.C.C building, non-linear analysis has become common these days. This analysis provides safety against earthquakes and other natural disasters. This method is also applicable with the pre-stressed concrete.

With the passage of time many advanced technology and computers have come up. Combination of all this with computer programming of methods of analysis helps in analyzing domain within short period of time as compare to the time consumed by the manually. The FEM has become powerful tool, in which complex domain may be analyzed for the nonlinear response with defined boundary conditions in short time. The crack initiation, cohesion and many more like parameters has leaded a revolution in the use of finite element method.

\section{E. Masonry infill frame modeling data}

To investigate the objectives of this study it is necessary to model the domain as like real life case. The domain is checked for a particular earthquake acceleration data of "Trinidad-Offshore Earthquake" occurred in the November 8, 1980. For maintain the real properties of the material and interaction between brick and mortar bed, parameters have considered accordingly results of the past study.

Description of Model: -

1. A box of $(3.5 \mathrm{~m} * 3 \mathrm{~m})$ is modelled for the study.

2. Thickness of the wall is 1 brick wall i.e. . $01 \mathrm{~m}$.

3. Mortar bed is of $12 \mathrm{~mm}$ with mortar ratio of 1:3.

4. Fe-415 steel of $8 \mathrm{~mm}$.

5. $\mathrm{C} / \mathrm{C}$ vertical spacing of reinforcement is $.3 \mathrm{~m}$.

6. L shaped reinforcing bar in plan having $8 \mathrm{~mm}$ in diameter.

7. Length of the bar is $2 \mathrm{~m}$.

Earthquake Data: -

Source: CESMD strong motion data (http://www.strongmotioncenter.org/) "Trinidad-Offshore Earthquake" acceleration data has used. Earthquake occurred in the November 8, 1980.
$\mathrm{ML}=6.9$
$\mathrm{MS}=7.2$
$\mathrm{MB}=6.2$
Peak Acceleration $=-326.247 \mathrm{~m} / \mathrm{s}^{2}$

1 Model of Brick-

The concrete damage plasticity may be used for defining brick material like plain concrete.

\section{Concrete Damage Plasticity:}

As the name is indicating in this technique both damage mechanics and plasticity are given as input for defining the actual behavior of the model. The basic objective is to draw a model which can clearly show the failure characteristics of concrete under multi axial loading. For fulfilling the requirements in modelling, 
combining an effective stress based plasticity model with a damage model based on plastic and elastic strain. The model response in compression i.e. uni-axial, bi-axial and in trial-axial and in tension is compared to the experimental results. The model defines the increase in strength and displacement capacity for increasing the confirmation levels. Furthermore the model is checked for compressive and tensile behavior for accurate structural analyses. The model i.e. CDP (concrete damage plasticity) that we used in the Abaqus software is the modification of Drucker-Prager strength Hypothesis. Afterwards, this drucker prager strength hypothesis many researchers had worked on it and modified the guidelines accordingly. Modifications over the time done by researchers tell that the failure surface in the deviatoric cross section needs not to be a circle and it is governed by the parameter Kc.

Kc: - The distance between the hydrostatic axis / respectively the tension meridian and compression meridian in the deviatoric cross section. Value of this parameter is always greater than .5 and when this value is assumed to be 1 , the deviatoric cross section of the failure surface becomes a circle. ${ }^{11}$ Lee (1998), reports that according to the experimental results this value for the mean normal stress equal to zero amounts to 0.6 and as there is decrease in the mean stress value it results in increase of value. The CDP model recommends to assume $\mathrm{Kc}=2 / 3$. This was resulted from the output of triaxial stress test and is a theoretical test.

There are many parameters defining the behaviour of concrete. One of them which tells about the state of the material at which point concrete undergoes failure under biaxial compression $\sigma \mathrm{b} 0 / \sigma \mathrm{c} 0$ (fbo/fco) is the ratio of the strength in the biaxial state to the strength in the uni-axial state. The most reliable in this regard are the experimental results reported on which results were verified. After this approximation with the elliptic equation, uniform biaxial compression strength fcc is equal to $1.16248 \mathrm{fc} 0$. The ABAQUS user's manual defines default of $\sigma \mathrm{b} 0 / \sigma \mathrm{c} 0$ as 1.16 .

Dilation angle- In the plastic shearing process it results in plastic volumetric strain which is controlled by the dilation angle. And dilation angle is assumed to be a constant during the plastic yielding. Also to know at which angle the failure surface is intersecting with horizontal i.e. hydrostatic axis it is measured in meridional plane. Often, dilation angle $¥$ is represented as a concrete internal friction angle. Usually $¥=36^{\circ}$ or $40^{\circ}$ are the general values that one assumes in design. The biggest and reliable advantage of the CDP modeling is that the method is totally reliable on parameters having an explicit physical interpretation. The parameter defining the exact role of patent material and all the mathematical method, that one use in Abaqus for defining a boundary conations to the domain in 3-D are explained in Abaqus user manual. The other parameters describing the performance of concrete are determined for unaxial stresses. Parameters value used are:-

\begin{tabular}{|l|l|}
\hline Parameter Name & Value \\
\hline Dilation angle & 36 \\
\hline Eccentricity & 0.1 \\
\hline fbo/fco & 1.16 \\
\hline K & .667 \\
\hline Viscosity parameter & 0 \\
\hline
\end{tabular}

\section{Modeling And Analysis}

In this case of modelling, simple analysis of a masonry wall needs to carry up. This is all because to ensure the presence of reinforcement in the corner regions can provide box action strongly and can improve its stresses carrying capacity along with all other advantages over wall without reinforcement in corner region. Modelling also ensures the results by satisfactory macro modelling in both cases. The modelling work is divided into two parts. The part-1 is modelling of masonry infill frame without steel reinforcement in the corner region. And the part-2 is modelling of masonry infill frame with steel reinforcement in the corner region.

\section{F. Case-1: Masonry infill wall box}

All dimensions are in $(\mathrm{N}, \mathrm{m})$.

Steps for modelling masonry infill without reinforcement are as follows-

1. Go to the module Part.

a) Create part-1 named as "half brick masonry".

2. Go to the module Property.

a) Create material named as "masonry", defining its density and elasticity.

$$
\text { Density }=2000 \mathrm{~kg} / \mathrm{m}^{3} \quad \text { Elasticity }=118 \mathrm{MN} / \mathrm{m}^{2}
$$

Poisson's ratio $=.15$

b) Defined concrete damaged plasticity

Plastic behavior.

Damaged behavior.

c) Assign section. 


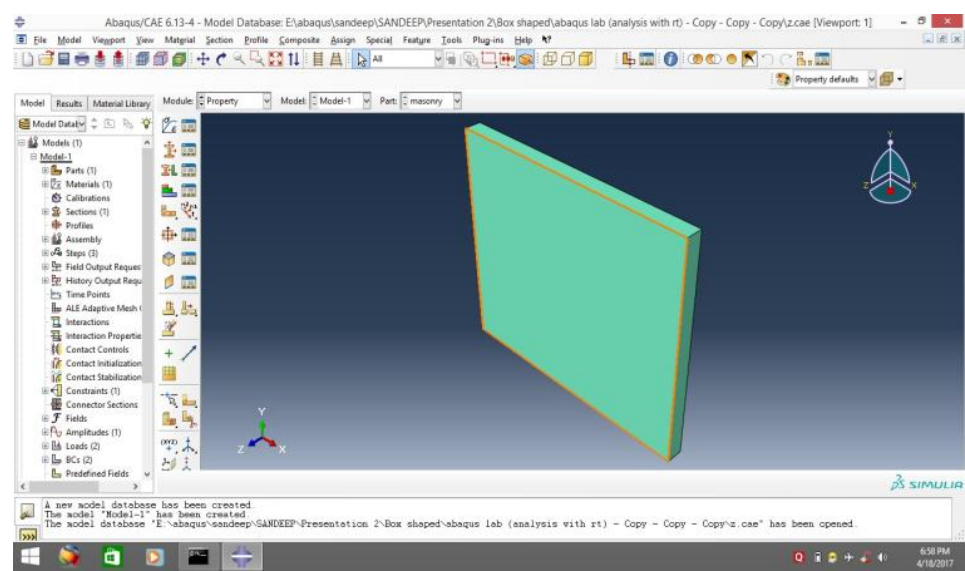

3. Go to the module Assembly.

a) Create instance: Here geometry of the object is created. Linear pattern, translate instance and rotate instance helps to set up the geometry.

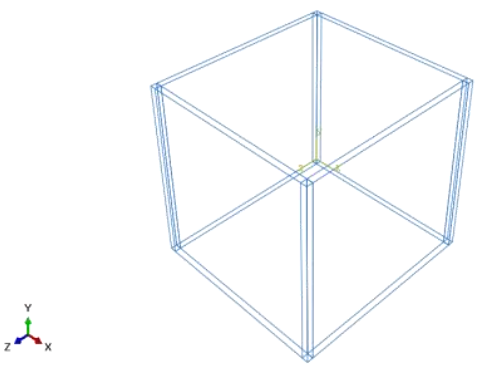

4. Go to the module "Step".

a) In the step manager create steps. Here default initial step automatically generates and two more steps i.e. Eigen and Seismic are defined in this modelling. For the Seismic case earthquake acceleration data has been defined. "Trinidad-Offshore Earthquake" acceleration data has used. Earthquake occurred in the November 8, 1980.
$\mathrm{ML}=6.9$
$\mathrm{MS}=7.2$
$\mathrm{MB}=6.2$ Peak
Acceleration=-

$326.247 \mathrm{~m} / \mathrm{s}^{2}$

b) In the field output manager defining the parameters as we want to manipulate the results.

5. Go to the module "Interaction".

a) Here we need to define the connection between the wall to wall contacts.

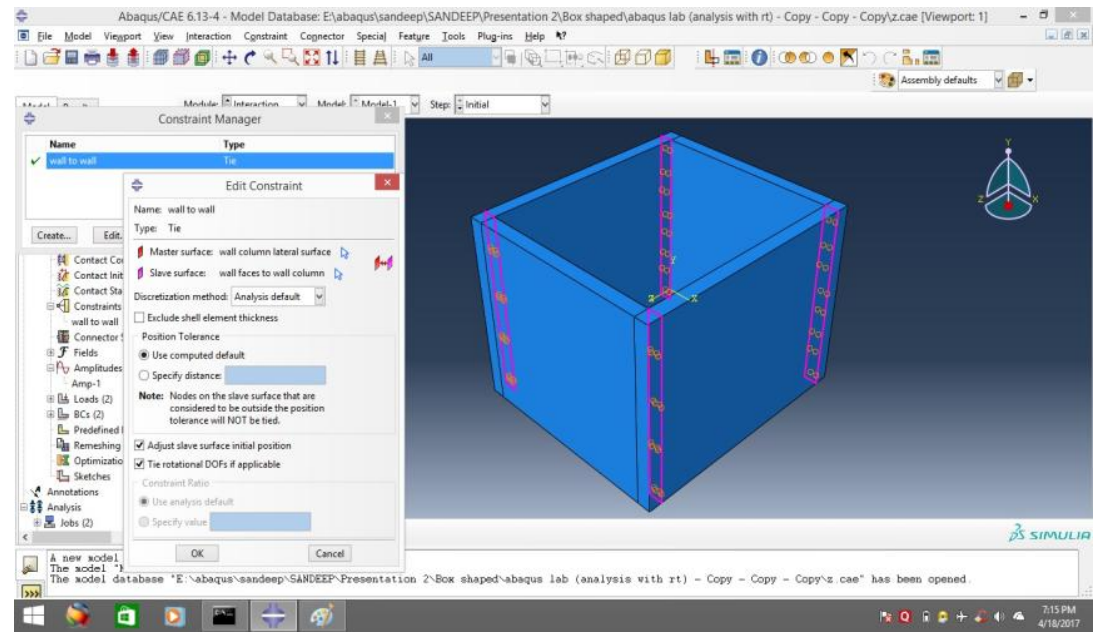

6. Go to the module "Loading".

a) Here defining the dead load and live load coming over the box for the seismic load.

b) Defining the boundary condition for both the steps. 
7. Go to the module "Mesh".

a) Meshing by parts or assembly depending upon the need as defined in the assembly case.

b) Defining seeds.

c) Setting the element type for the meshing.

d) Creating the instance and controlling the mesh.

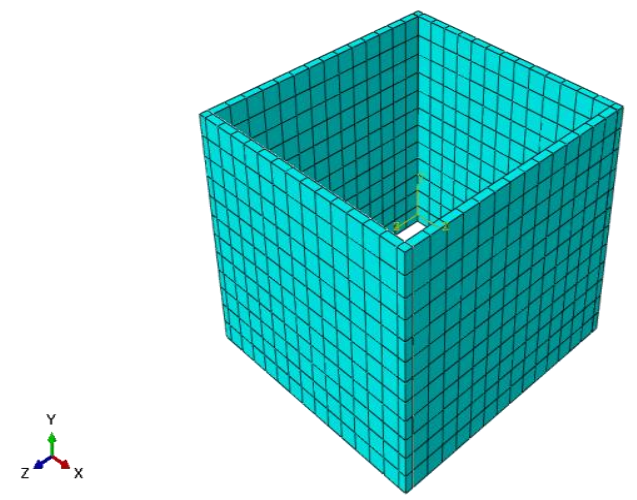

8. Go to the module "Job".

a) Creating job and thus submitting the data.

b) After completion go for the results.

\section{G. Case-2: Masonry infill wall box with reinforcement in corner.}

All dimensions are in $(\mathrm{N}, \mathrm{m})$.

Steps for modelling masonry infill with reinforcement are as follows-

1. Go to the module Part.

a) Create part-1 named as "half brick masonry".

b) Create part-2 named as "rebar".

2. Go to the module Property.

a) Create material named as "masonry", defining its density and elasticity.
Density $=2000 \mathrm{~kg} / \mathrm{m}^{3}$
Elasticity $=118 \mathrm{MN} / \mathrm{m}^{2}$

Poisson's ratio $=.15$

b) Defined concrete damaged plasticity

Plastic behavior.

Damaged behavior.

c) Create material named as "rebar", defining its density and elasticity.
Density $=7850 \mathrm{~kg} / \mathrm{m}^{3}$
Elasticity $=200 \mathrm{GPa}$
Poisson's ratio $=.3$

d) Assign sections.

3. Go to the module Assembly.

a) Create instance.

Here geometry of the object is created. Linear pattern, translate instance and rotate instance helps to set up the geometry. Also

Portioning helps in connection walls at the corner regions.

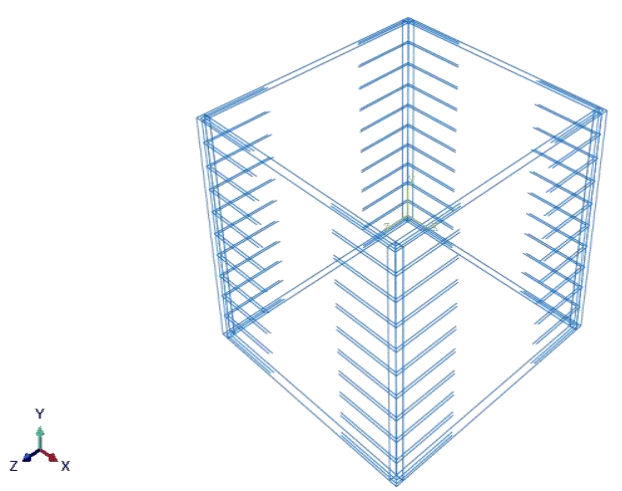


4. Go to the module "Step".

a) In the step manager create steps. Here default initial step automatically generates and two more steps i.e. Eigen and Seismic are defined in this modelling. For the Seismic case earthquake acceleration data has been defined. "Trinidad-Offshore Earthquake" acceleration data has used. Earthquake occurred in the November 8, 1980 .
$\mathrm{ML}=6.9$
$\mathrm{MS}=7.2$
$\mathrm{MB}=6.2$ Peak
Acceleration=-

$326.247 \mathrm{~m} / \mathrm{s}^{2}$

b) In the field output manager defining the parameters as we want results.

5. Go to the module "Interaction".

a) Here we need to define the connection between the wall to wall contacts and the reinforcement relation with the surrounding material.

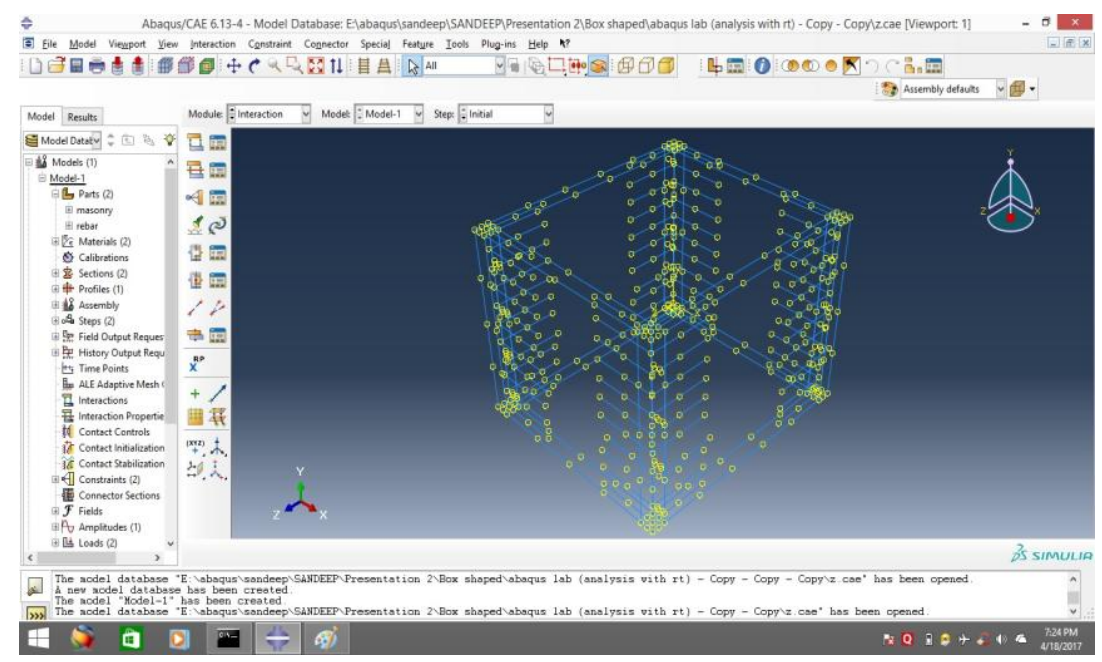

6. Go to the module "Loading".

a) Here defining the dead load and live load coming over the box for the seismic load.

b) Defining the boundary condition for both the steps.

7. Go to the module "Mesh".

a) Meshing by parts or assembly depending upon the need as defined in the assembly case.

b) Defining seeds.

c) Setting the element type for the meshing. Creating the instance and controlling the mesh.

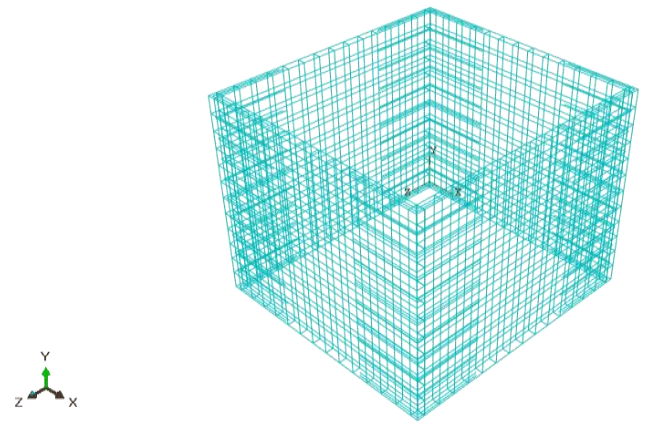

8. Go to the module "Job".

a) Creating job and thus submitting the data.

b) After completion go for the results.

\section{Results And Discussion}

In this, result of the finite element analysis of the masonry infill frame for a particular earthquake acceleration data has been performed using the Abaqus software. Results of the masonry infill frame with and without steel reinforcement in the corner region are compared. After that behavior of stresses, displacement and forces have studied. 


\section{H. Finite Element Results of Masonry Infill Wall}

After following all the steps of modelling and analyzing model for a particular defined acceleration data the different parameters have studies here. First of all let's discuss about the expected failures of the masonry infill walls. This will be shown by contour graphs.

Stress concentration in the masonry infill wall leading to the crack initiation at respective position. When forces are distributed uniformly over an area the object is said to be strong or rigid. In the stress concentration, area for distribution of forces becomes less and cause localized increase in stress. Now when the generating stresses become greater than material's strength, crack initiation takes place. This zone of stress concentration also leads to fatigue stresses. Sometimes to overcome this defect results in better strength. The main parameter reflected are-

Corner crushing in the masonry infill wall.

Diagonal cracking.

Shear failure.

Out of plane failure.

In plane failure.

\section{B. Expected Failures of the Masonry Infill Walls}

Before talking about the final output results it is necessary that the modelled domain will show some basic expected failures so that one can be reliable for final results obtained.

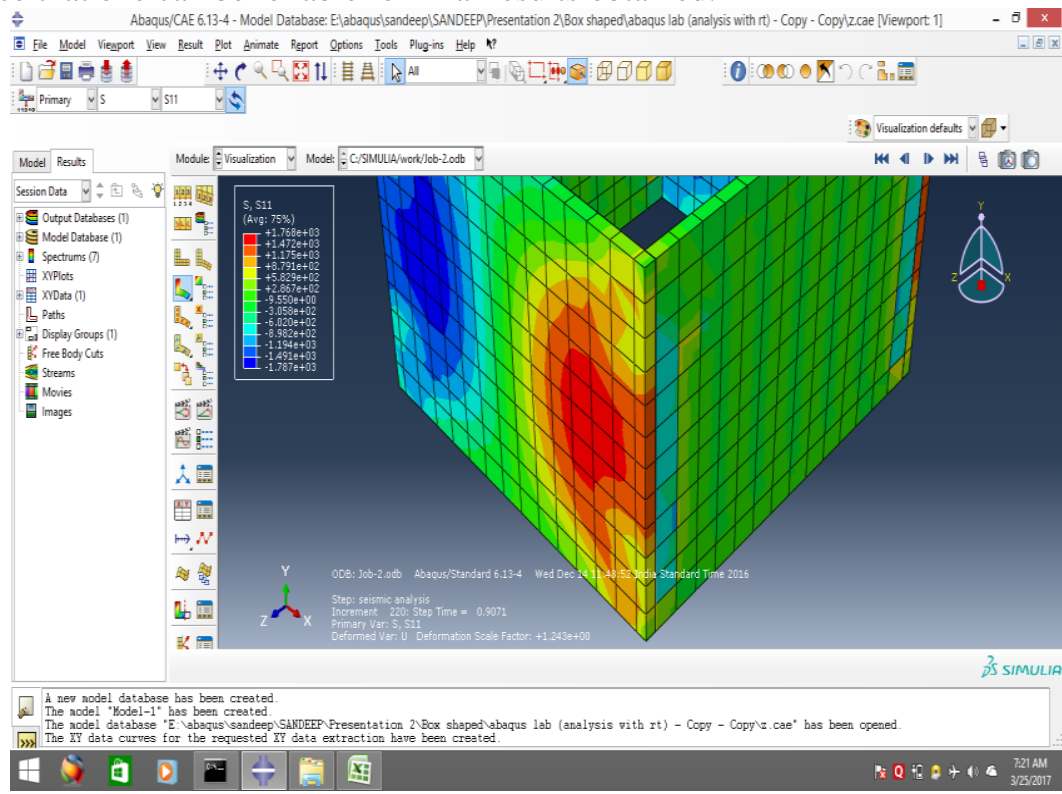

(i) Stress Concentration.

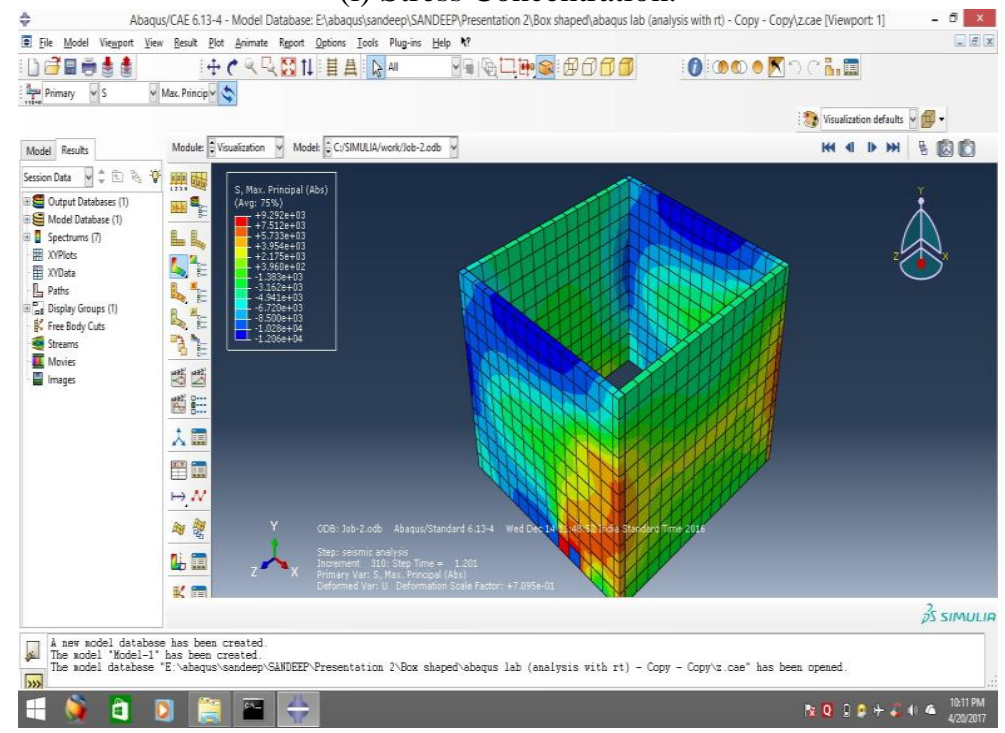

(II) Diagonal Cracking. 

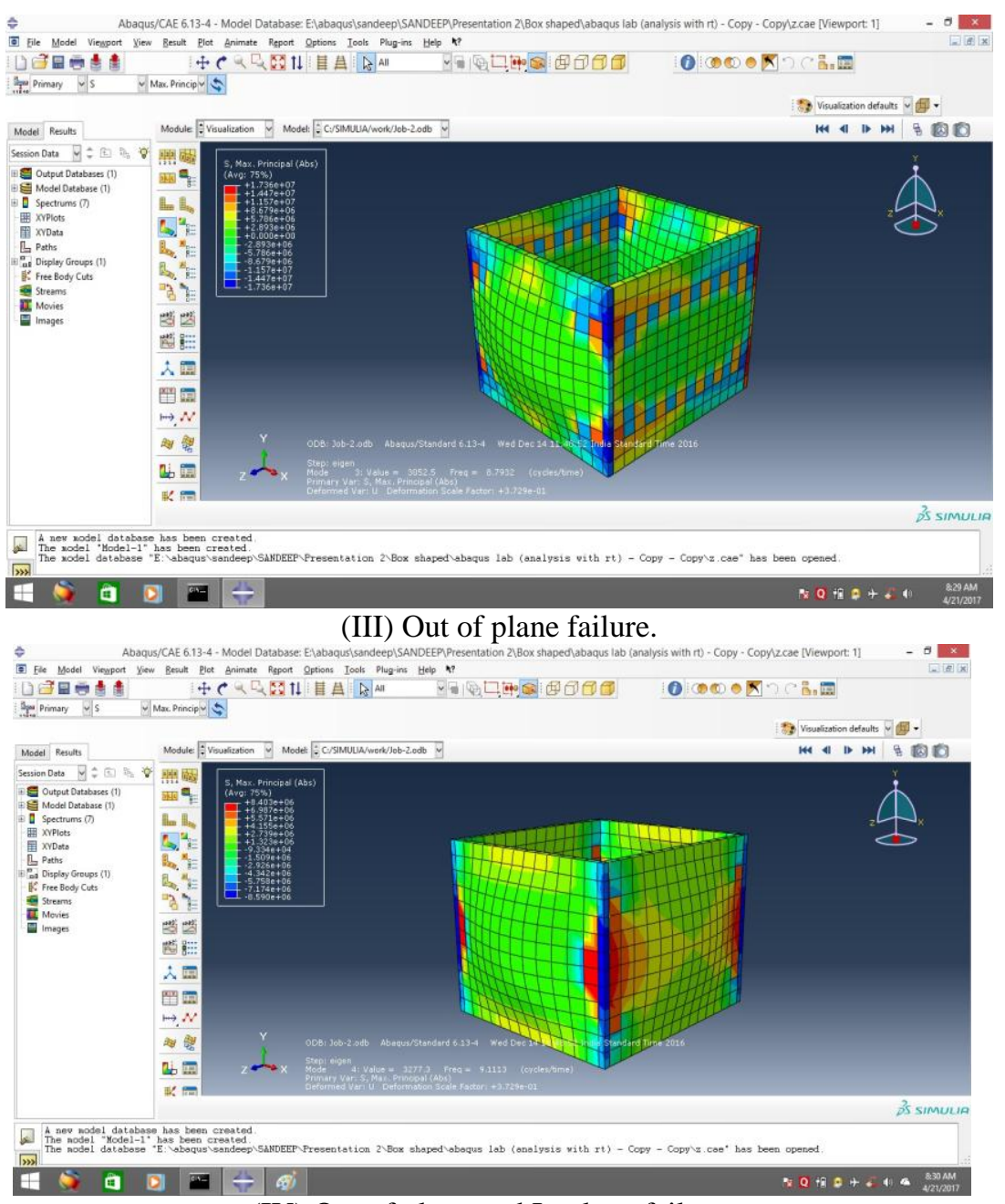

(IV) Out of plane and In plane failure.

\section{Resulted Graphs}

Different parameters have studied to quantify the final results. Some of them are as follows-

1. Base shear vs. Displacement

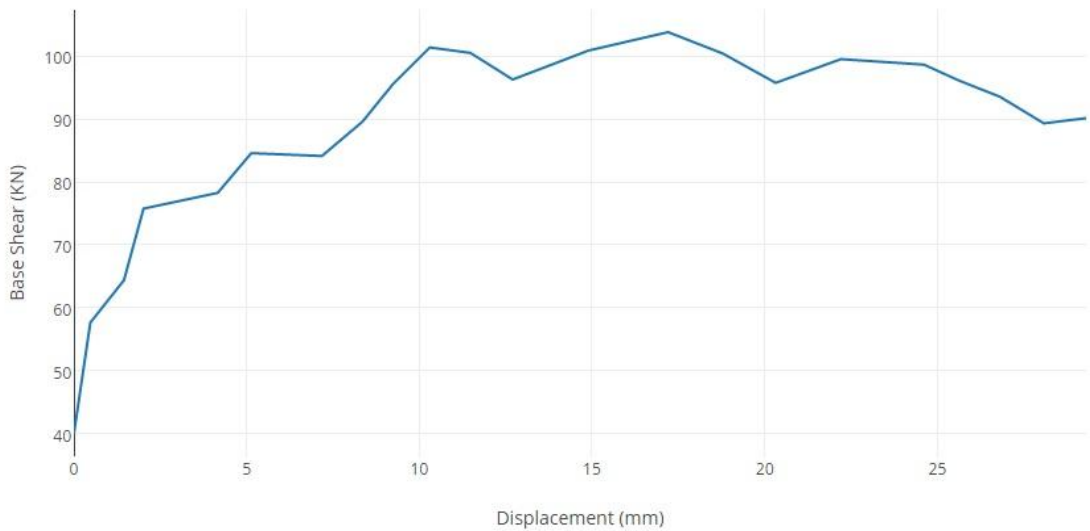

(I) Case-I 


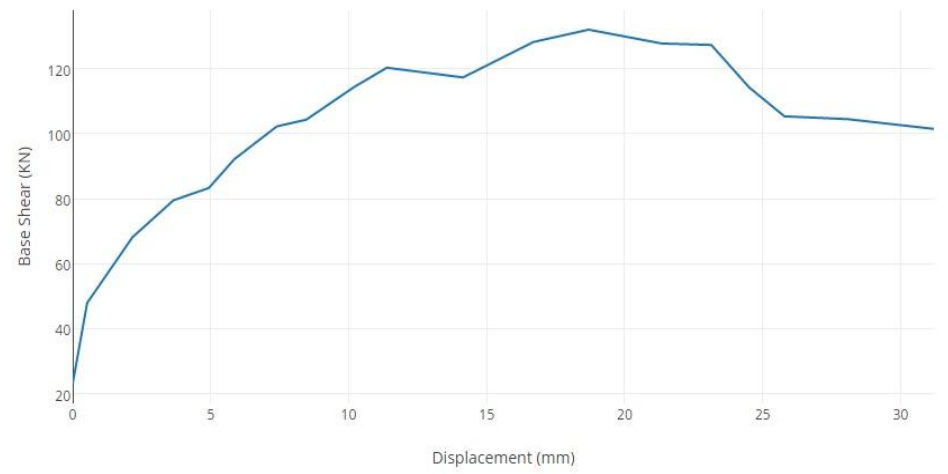

(II) Case-II

From the load displacement curve shown above it clearly shows that the:

i. Curve is growing smoothly in case-2 while in the case-1 it is increasing with sharp increase and decrease. This sharpness is indicating the crushing of brick units and displacing off from their original position.

ii. In the case-2 lateral load carrying capacity improves and it is approximately $130 \mathrm{KN}$ and in the case- 1 it is approximately $102 \mathrm{KN}$.

iii. Area under case-2 is more than case-1, simply implies that energy dissipation is more in case-2.

2. Normal Stress : At same node position

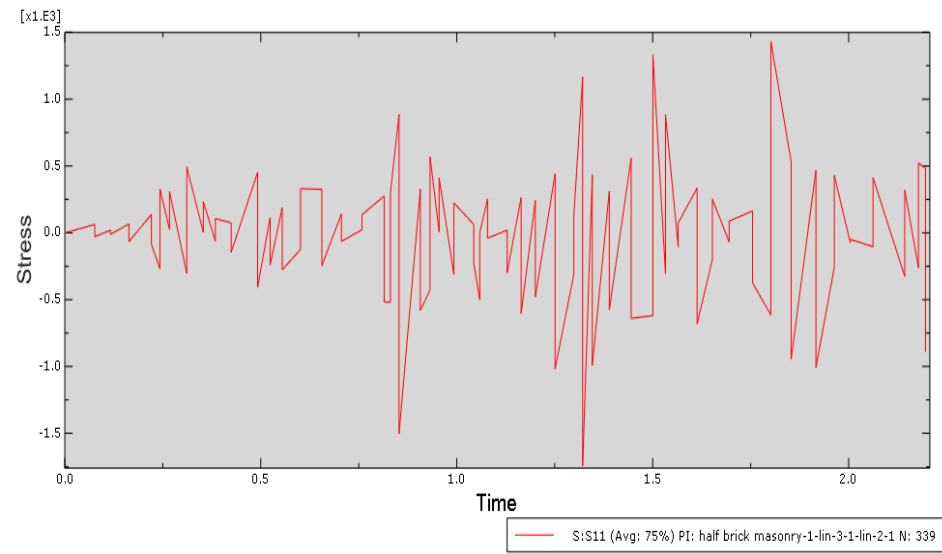

(I) Case-I

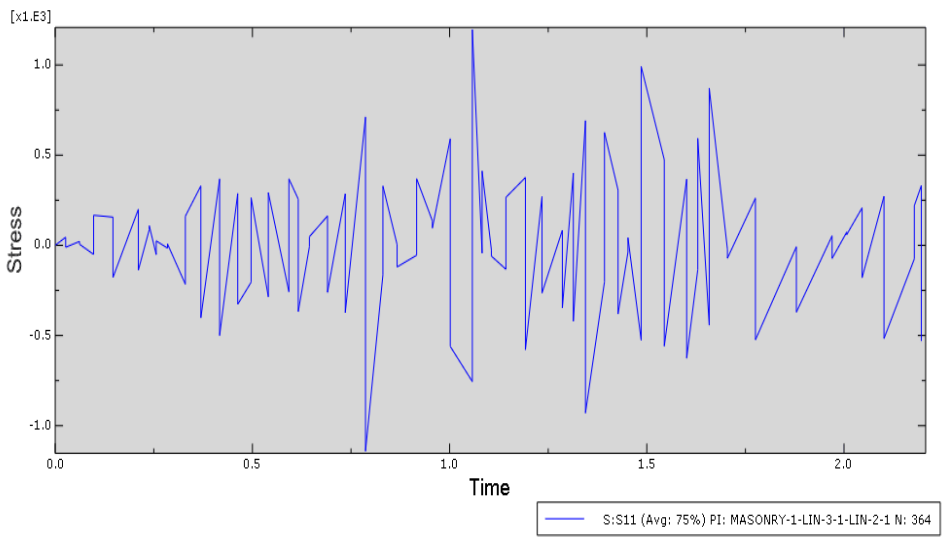

(II) Case-II

The above graphs of normal stresses clearly show that the:

i. Shear Force of $1750 \mathrm{~N}$ in case-I, which is reducing to nearly $1250 \mathrm{~N}$ in the case-II.

3. Displacement : At same node position 


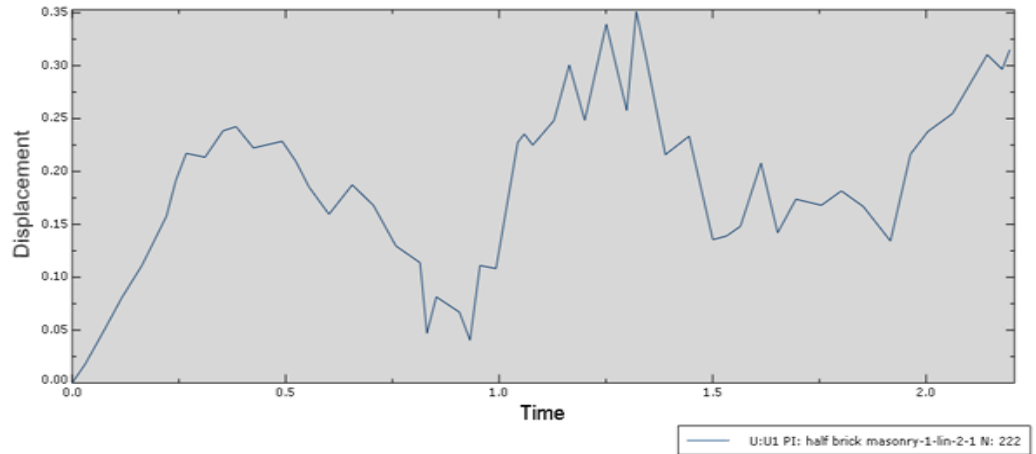

(I) Case-I

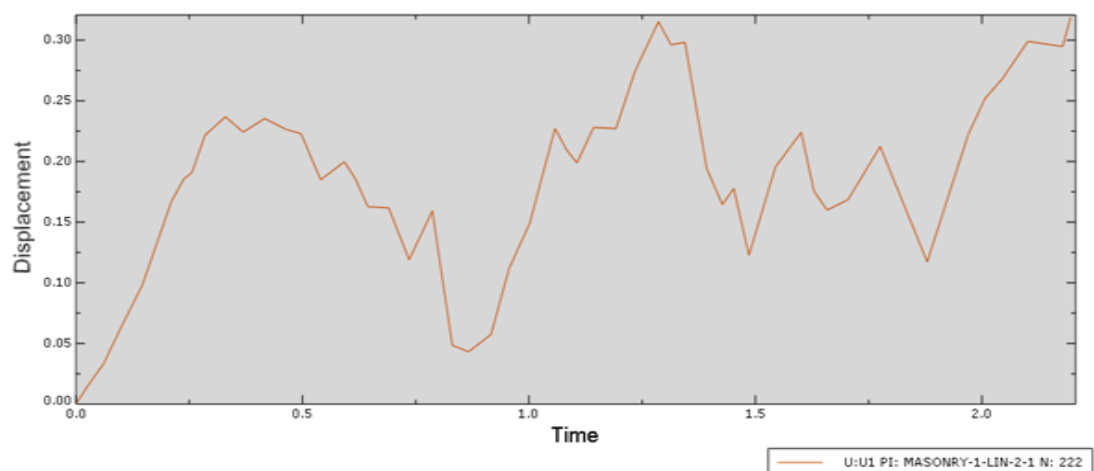

(II) Case-II

The graphs of displacement clearly show that the:

i. Displacement of $350 \mathrm{~mm}$ in case-I, which is reducing to nearly $320 \mathrm{~mm}$ in the case-II.

4. Shear Stresses : At same node position

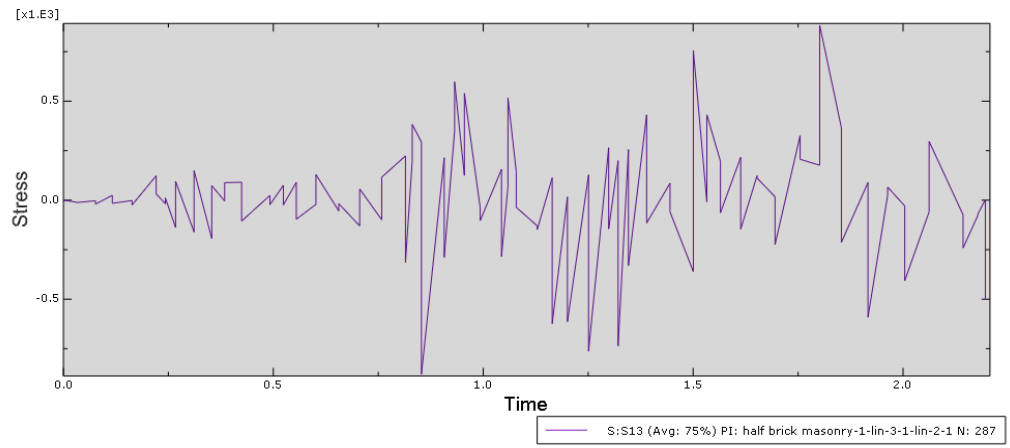

(I) Case-I

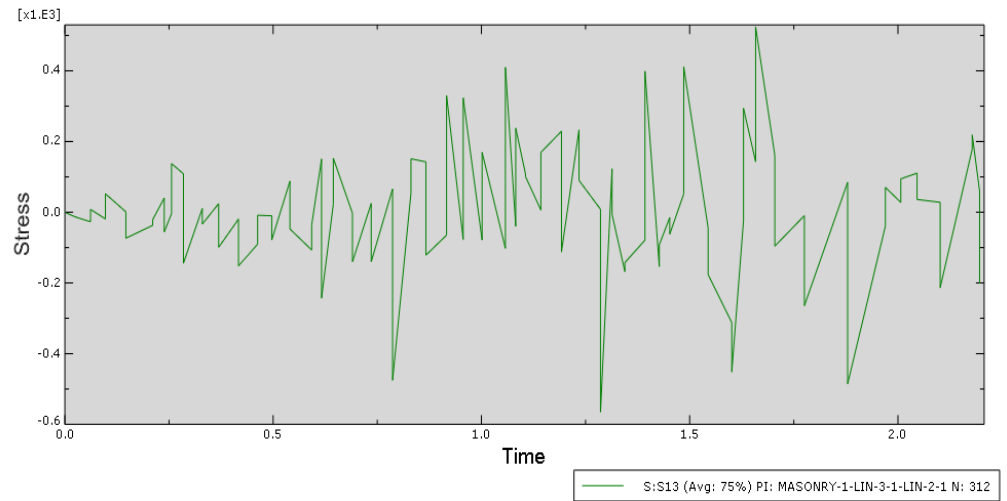

(II) Case-II 
The graphs of shear stresses clearly show that the:

The nature of the shear stress varying is more at the mid height than at top and bottom of wall. According to the graph of shear stress for case-I, maximum shear stress is $800 \mathrm{~N} / \mathrm{m}^{2}$.

This graph of shear stress for the case of masonry infill with reinforcement at corner shows that the nature of the shear stress is reducing in this case. The maximum shear stress is $600 \mathrm{~N} / \mathrm{m}^{2}$. Hence reduction in shear stress is observed.

\section{Results}

To find the changes in both cases, values of displacement, shear force and shear stress is computed in the tabular form for both cases in different node positions. Obtained results are satisfactorily at all nodes. Generally the behavior that comes to see are-

1. To increase in the strength.

2. Decrease in the final deflection.

3. Increase in the energy dissipation.

4. Variation of results in case-I and in case-II are lying in the range of 4-28\%.

5. At some node positions results are not coming satisfactorily. This may be due to the stress concentration which is finally leading to the crushing of the material.

6. Maximum response of different parameters is coming in the mid height of the corner region.

\section{Conclusion}

Based on the old researches, different modes of failure of masonry infill walls also considered and have been checked for the failure mechanism occurring here. From the analysis results, firstly it is concluded that as like possible mode of failures of masonry infill wall there is stress concentration taking place. This stress concentration is varying with time and taking place at different positions. Cracks initiation due to localized shear failure occurs in the different sections of model in the analyzed results. Also crushing of the masonry infill walls in the corner region occurring. The resulted failure i.e. crushing in corner region have not any particular well defined failure point just because after cracking the wall can take reversal loads and gravity loads. The in-plane and out of plane failure also capturing in the mode shapes of the model analyzed.

Instead of using equivalent strut system for the Macro modelling, a simple wall system is adopted. The behavior of elastic and deformation limits of masonry has assigned to this. And the expected general failures have captured in the final analysed results. So this is believable to consider the outputs of analyzed model.

The resulted graphs, contours and tables have clearly mentioned in the last chapter that placing of reinforcement in the corner region of masonry infill wall improves the connection behavior. As result of this improve connection system there is increase in the shear force, shear stress and energy dissipation of the system. Deflection limits at the corner regions also improving due to presence of reinforcements.

This technique of placing reinforcement in corner region is satisfactorily as resulted in this study. The placement of reinforcement can be done during construction time in layer wise. Also one can place reinforcement for improving connection response in old constructed masonry wall by using crack stitching technique of retrofitting.

\section{References}

[1]. Maske, Sachin G., and Dr PS Pajgade. "Torsional Behavior of Asymmetrical Buildings." International Journal of Modern Engineering Research, ISSN (2013): 2249-6645.

[2]. Essa, Ahmed Sayed Ahmed Tawfik, Mohamed Ragai Kotp Badr, and Ashraf Hasan El-Zanaty. "Effect of infill wall on the ductility and behavior of high strength reinforced concrete frames." HBRC Journal 10.3 (2014): 258-264.

[3]. Dizhur, Dmytro, Michael Griffith, and Jason Ingham. "Out-of-plane strengthening of unreinforced masonry walls using near surface mounted fibre reinforced polymer strips." Engineering structures 59 (2014): 330-343.

[4]. R.Allouzil, A.Irfanoglu, and G. Haikal. "Non linear finite element modelling of RC frame masonry wall interaction under cyclic loading." Tenth U.S. National Conference on Earthquake Engineering Frontiers of Earthquake Engineering (10NCEE).

[5]. Kaushik, Hemant B., Durgesh C. Rai, and Sudhir K. Jain. "Stress-strain characteristics of clay brick masonry under uniaxial compression." Journal of materials in Civil Engineering 19.9 (2007): 728-739.

[6]. Pandey, Bishnu Hari, and Kimiro Meguro. "Simulation of Brick masonry wall behavior under in plane lateral loading using applied element method." 13th World conference on earthquake engineering, Vancouver, BC, Canada, August. Vol. 16. 2004.

[7]. $\quad$ Asteris, P. G. "Finite element micro-modelling of infilled frames." Electronic Journal of Structural Engineering 8.8 (2008): 1-11.

[8]. Madan, A., et al. "Modelling of masonry infill panels for structural analysis." Journal of Structural Engineering 123.10 (1997): 1295-1302.

[9]. Bell, D. K., and B. J. Davidson. "Evaluation of earthquake risk buildings with masonry infill panels." 2001 Technical Conference, Future Directions: A Vision for Earthquake Engineering in New Zealand. 2001.

[10]. $\quad$ Polyakov, S. V. "On the interaction between masonry filler walls and enclosing frame when loaded in the plane of the wall." Translations in earthquake engineering 2.3 (1960): 36-42.

[11]. Lee, Jeeho, and Gregory L. Fenves. "Plastic-damage model for cyclic loading of concrete structures." Journal of engineering mechanics 124.8 (1998): 892-900.

[12]. http://129.97.46.200:2080/v6.13/ Abaqus 6.13 Documentation.

[13]. http://dsk.ippt.pan.pl/docs/abaqus/v6.13/books/usb/default.htm Abaqus Analysis User's Guide (6.13). 